\title{
PROXECTO PARA UN OBSERVATORIO DA ARQUEOLOXÍA PROFESIONAL: A ADMINISTRACIÓN GALEGA ${ }^{1}$
}

\author{
MARÍA CACHEDA PÉREZ \\ Laboratorio de Arqueoloxía, Instituto de Estudios Galegos "Padre Sarmiento", \\ (CSIC-Xunta de Galicia)
}

\section{Resumo}

O Observatorio da Arqueoloxía Profesional en España ten como obxectivo básico crear unha base de dados tanxíbel sobre as actividades arqueolóxicas desenvolvidas no marco comercial, contractual e profesional en España, debido a desinformación e fragmentación da Arqueoloxía como préstamo de servizos.

Xurde coma un intento de centralizar a información e convertela en coñecemento accesibel e manipulabel, tanto para arqueólogos profesionais, investigadores ou xente interesada na actividade arqueolóxica.

Para a consecución destes obxectivos estabelecerase unha metodoloxía baseada en distintos criterios: deseñaríanse enquisas dirixidas a Administración, aos profesionais independentes e outra ó sector académico.

Preséntanse os primeiros resultados da enquisa realizada na Administración Galega.

\section{Palabras clave}

Observatorio, Arqueoloxía Profesional, Galiza, Servizo de Arqueoloxía, Base de datos, Enquisa.

\footnotetext{
${ }^{1}$ Data de entrega en secretaría: abril 2006.
}

\begin{abstract}
The paper of this essay is present a tangible database to try centralize the information about Comercial Archeology in Spain.

The ultimate is to turn the database into accessible and operable knowledge from professional archaeologist, investigators and people interested about the subjet in question. Anyone interested acquired a thorough knowledge of archaeologist work in Spain.

I present the metodology conjuged in the study and the results obtains in a first fact systematization.
\end{abstract}

\section{Keywords}

Observatory, Professional Archaeology, Galicia, Archaeology Service of the Autonomous Communities, database, questionnaire. 


\section{ANTECEDENTES}

A publicación da Constitución Española de 1978 supuxo unha nova organización para o Estado: dunha Administración única pasouse a dezaoito, o que supuxo unha reorganización da administración do Patrimonio Cultural e Arqueolóxico, co que aumentou a dificultade dunha xestión integral. En cada comunidade autónoma (17) existe unha Dirección Xeral (ou dous, como en Andalucía ou Madrid) dedicadas a protección do Patrimonio Cultural, con servizos especializados que se encargan da xestión do Patrimonio Arqueolóxico.

Ademais tamén xestionan o Patrimonio Arqueolóxico administracións locais e as corporacións municipais (a través do planeamento do territorio, a educación, a vixilancia...) e a ciudadanía en xeral (coa explotación do chan urbano e rural).

A principios dos 80 se levou a cabo a transferencia de competencia exclusiva en materia de Patrimonio Arqueolóxico e a súa xestión as diferentes Comunidades Autónomas, que a partir de 1990 foron publicando as súas propias leis. As tarefas da Administración do Estado son a loita contra o expolio e a coordinación das administracións autonómicas.

\section{INTRODUCIÓN E OBXECTIVOS}

Na xuntanza realizada entre o 29 de xaneiro e o 1 de febreiro de 2004 en Santiago de Compostela, entre os membros da executiva do EAC (Europae Archaeologiae Consilium) e os responsabeis dos Servizos Arqueolóxicos das distintas Comunidades Autónomas do país, presentouse o proxecto para a creación do Observatorio para a Arqueoloxía Profesional no Estado Español, que se está a comezar a por en marcha. Este proxecto consiste en tentar cubrir a crecente necesidade dun banco de dados tanxíbel, que integre información variada sobre as actividades arqueolóxicas desenvolvidas no marco comercial, contractual e profesional da Arqueoloxía en España. Esta necesidade provinte do actual estado de desinformación e fragmentación da Arqueoloxía concebida como prestación de servizos (un exemplo: non se sabe canto diñeiro move a arqueoloxía de servizo no Estado). O Observatorio xurde como un intento de centralizar a información e convertela en coñecemento accesibel e manipulabel, tanto para arqueólogos profesionais e investigadores como para xente interesada na actividade arqueolóxica española.

Nunha primeira fase se pretende recabar no campo da Administración, unha serie de datos básicos acerca da actividade da arqueoloxía profesional en cada Comunidade Autónoma. 


\section{METODOLOXÍA E PLAN DE TRABALLO}

Para a consecución destes obxectivos estableceuse unha metodoloxía baseada en distintos criterios:

- Mediante un primeiro momento de deseño, pretendíase obter unha enquisatipo que recollese a información considerada relevante. Dita enquisa, dirixida a administración, orientaríase a obtención de datos relativos ao funcionamento xeral da actividade arqueolóxica de servizos no seu ámbito correspondente: volume de traballo global, parámetros de calidade, integración de resultados, etc. Dado que é a administración o ámbito prioritario de obteción de datos será aquí onde se concentren os maiores esforzos e onde a información será recabada de forma exaustiva.

- O momento de realización da enquisa ocuparía boa parte desta primeira fase de implementación do observatorio, xa que habería que porse en contacto con distintas administracións de Patrimonio en todo o Estado. A metodoloxía debería tender sempre a minimización de esforzos e a maximización de resultados.

- O momento de sistematización da información obtida durante a enquisa, que pecharía esta primeira fase do estudo.

- As perspectivas para fases posteriores apuntan a unha informatización de toda a información recabada e a creación dunha base de datos accesíbel na Web.

\section{DESEÑO DA ENQUISA}

García Ferrando (1993: 141) define a enquisa como "unha técnica que utiliza un conxunto de procedementos estandarizados de investigación mediante os cales se recollen e analizan unha serie de datos dunha mostra de casos representativa dunha povoación ou universo máis amplio, do que se pretende explorar, describir, predicir elou explicar unha serie de características".

O proceso xeral seguido neste traballo para a investigación mediante unha enquisa se basea no método de Oppenheim que distingue unha serie de etapas para iso e que están recollidas en Rojas Tejadas et al. (1998) e que utilizamos en maior ou menor medida dependendo das necesidades. Os pasos seguidos foron os seguintes:

1. Determinar os obxectivos da enquisa concretados nunha serie de obxectivos operacionais para a futura investigación sobre o desenvolvimento da arqueoloxía profesional en España.

2. Revisar a bibliografía específica do tema a investigar. 
3. Decidir cales ían ser as hipóteses específicas que se ían investigar nesta fase, chegando a conclusión de que nos interesaba a xestión do Patrimonio Arqueolóxico e a actividade arqueolóxica profesional contada a través das Administracións das diferentes Comunidades Autónomas.

4. Establecer o tipo de mostra que se ía a enquisar, que serían as dezasete autonomías.

5. Selecionar a xente que se ía a enquisar: os xefes do Servizo de Arqueoloxía ou algunha persoa delegada por eles.

6. Elaborar a enquisa.

7. Realizar o traballo de campo. Levouse a cabo por medio de enquisa por email e por correo postal, apoiadas por chamadas telefónicas aos distintos Servizos de Arqueoloxía.

8. Reunir os resultados e contrastar hipóteses.

9. Reunir o informe da investigación coas conclusións obtidas.

A hora de enfrentarnos a elaboración do cuestionario tívose en conta que era un instrumento de recollida de datos que nos aportaría información estandarizada, fácil de interpretar e comparar pois os enquisados responderían ao mesmo conxunto de preguntas.

O cuestionario debería detallar as áreas de contido e especificar xeitos concretos en cada área con preguntas concretas e xustificadas para garantir a integridade da información.

Decidiuse facer un estudo piloto en xunio de 2004; despois de realizar varios bocetos para probar o cuestionario, no Servizo de Arqueoloxía da Comunidade Autónoma de Galiza. O deseño final foi revisado por distintos membros do Servizo de Arqueoloxía, concretamente por Manuel Rei García que suxeriu algúns cambios e cuestións non incluidas con anterioridade, como era o tema da Posta en Valor. O modelo de enquisa definitivo inclúe catro apartados principais: un sobre datos de organización e datos administrativos, outro sobre datos da estrutura profesional referintes a administración, a profesionais alleos a esa administración (empresas de arqueoloxía, autónomos...) e a profesionais vinculados a organismos académicos e museos. Outro apartado trata sobre cuestións de actividade arqueolóxica e, por último, un sobre proxectos de posta en valor.

\section{RESULTADOS NA GALIZA}

O Servizo de Arqueoloxía en Galiza parte dun organigrama que se inicia na Consellería de Cultura e Deporte, Dirección Xeral de Patrimonio Cultural, Institu- 
to de Conservación e Restauro de Bens Culturais e, dentro de éste, o Servizo de Arqueoloxía, onde traballaban doce profesionais, no momento en que se levou a cabo a enquisa.

As funcións que exerce o servizo son sobre todo de protección, divulgación, inventariado do patrimonio arqueolóxico, a través da posta en valor de varios xacementos arqueolóxicos, ademais de autorizar a actividade arqueolóxica e regularla.

En canto aos datos sobre o censo arqueolóxico, na administración galega se ten constancia dunhas vinte empresas formadas por dous ou tres arqueólogos e teñen contabilizados vintecatro autónomos.

A través dos datos ofrecidos sobre a actividade arqueolóxica, vemos que na Galiza no ano 2003 se levaron a cabo un total de 728 actuacións: 280 controlos arqueolóxicos, 274 prospeccións, 139 sondaxes e 38 escavacións (Figura 1). Ese mesmo ano realizáronse 195 actuacións en arqueoloxía urbana (Figura 2).

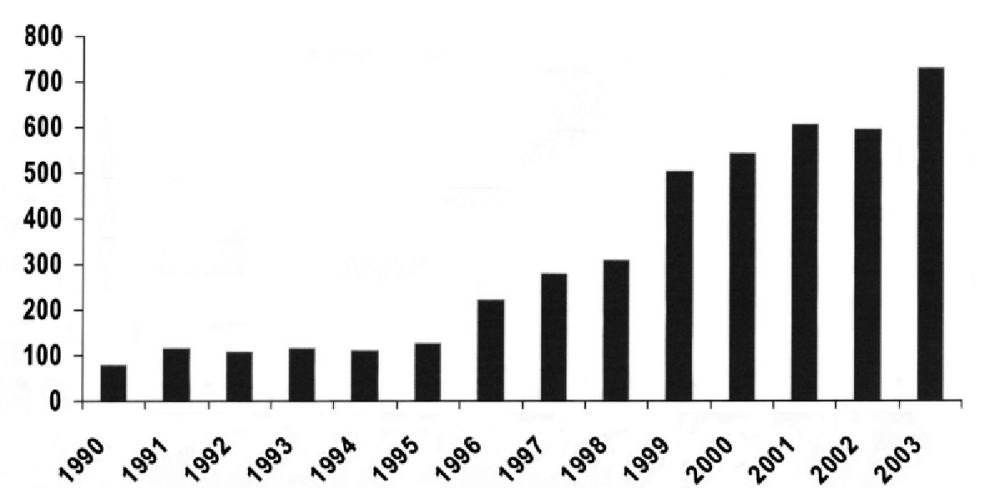

Figura 1: Actuacións Arqueolóxicas en Galiza. Fonte: Servizo de Arqueoloxía da Dirección Xeral de Patrimonio Cultural da Xunta de Galiza.

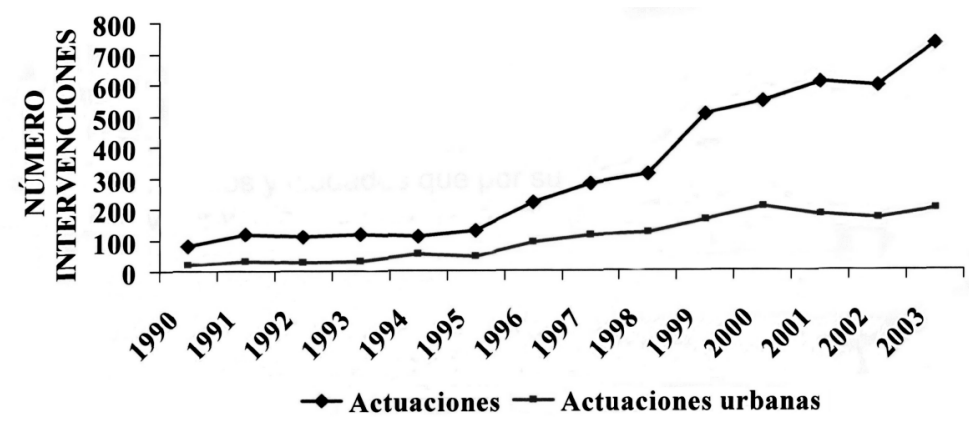

Figura 2: Arqueoloxía Urbana en Galiza. Fonte: Servizo de Arqueoloxía da Dirección Xeral de Patrimonio Cultural da Xunta de Galicia. 
Para valorar estes datos hai que ter en conta que a comunidade galega ten unha extensión de 29.575 quilómetros cadrados, está no sétimo lugar mais grande das dezasete autonomías. Todos estes datos xestiónanse a través dunha base de datos realizada cun sistema de información xeográfica e cun inventario técnico-administrativo para a protección e conservación. Este inventario atópase formado por un arquivo de xacementos arqueolóxicos ordenados por concellos e provincias, un arquivo de actuacións arqueolóxicas composto de informes e memorias e un último arquivo de actuacións en bens do patrimonio cultural como igrexas, monasterios ou castelos.

En Galiza a chamada Rede Galega do Patrimonio Arqueológico (RGPA, presentada en abril de 2001), constitúe un marco de actuación, un punto de encontro de todas as iniciativas, públicas e privadas, que se dean no ámbito da Protección, Posta en Valor e Divulgación dese Patrimonio, que se estaba a comezar a pór en marcha no momento en que se levou a cabo a enquisa, e que non se sabe do seu futuro debido o cambio político no goberno galego. Os xacementos arqueolóxicos que se integrarían na Rede constituirían os elementos visitabeis e organizaríase en catro "parques arqueolóxicos": parque arqueolóxico do megalitismo, da arte rupestre, da cultura castrexa e do mundo romano. Pretendería estructurar a posta en valor dos xacementos arqueolóxicos, optimizar os recursos dispoñíbeis para iso, divulgaría a información relacionada con xacementos creando infraestruturas expositivas, e impulsar a protección e conservación do Patrimonio Arqueolóxico.

\section{VALORACIÓN DOS RESULTADOS}

A arqueoloxía comercial representa un sector moi pequeno dentro da comunidade estudada e certamente non todos acceden a realidade do mercado de traballo, en mans da iniciativa privada que somete aos profesionais a unha inestabilidade permanente instrumentalizada polo capital e as grandes empresas. O sector arqueolóxico empresarial, formado por pequenas empresas de dous ou tres membros ten unha capacidade limitada xa que o traballo arqueolóxico depende da fluctuación do mercado do solo. A inexistencia de asociacións profesionais fortes fai que as empresas compitan a baixa en presupostos e honorarios, o que repercute na calidade do traballo e fai que as empresas non se consoliden nin medren.

O traballo do arqueólogo non é compensado polo seu coñecemento especializado se non que o cliente só quere que se eliminen as travas administrativas no menor tempo e o máis barato posíbel e así se libere o solo; a arqueoloxía convértese nunha instancia mais de control público sobre o mercado do solo. As intervencións priva- 
das son moitas e cada vez mais difíciles de controlar, as empresas tiran de datos publicados ou públicos e non chegan en ocasións a pisar o terreno. Sería imprescindibel contar con financiación adicional para cubrir aqueles gastos que permitisen rentabilizar as intervencións en termos de I+D e asi potenciar o desenvolvimento armónico do mercado e o coñecemento arqueolóxico: o sector público é o único capaz de exixir estándares de calidade e garantir a producción de resultados e a rentabilización dos mesmos en termos científicos e sociais.

Non hai posibilidade de crear empresas que teñan unha maior capacidade de afrontar intervencións importantes, co que os profesionais e a administración prefiren que os contratos se fagan a unha empresa constructora que pon os medios e materiais necesarios.

En xeral penso que se pode observar que a Administración non posúe un programa global que articule as intervencións arqueolóxicas puntuais, e a súa intervención é escasa unha vez posto en marcha o sistema: a súa tarefa baséase na concesión de permisos e na recepción de memorias, o que conleva un funcionamento cada vez mais liberal do exercicio dos implicados e a ausencia de control nas intervencións. Sen unha xestión efectiva e eficaz a calidade da intervención descende cada vez mais e só pode minimizarse mediante unha xestión efectiva da administración competente. Deberían exixir condicións e requerimentos mínimos para as intervencións, tentar que se cumpla a normativa e homoxeneizar as metodoloxías e sistemas de rexistro da información, ademais de fixar canais para a publicación dos resultados obtidos íntegra e obrigatoriamente. Somos moitas as arqueólogas/os que traballamos en Galiza e non sabemos o que é o que se está a facer.

A documentación xerada polas actuacións arqueolóxicas é arquivada a través dunha base documental, un inventario técnico-administrativo para a protección e conservación, formado pola información de xacementos arqueolóxicos de actuacións arqueolóxicas (informes e memorias) e de actuacións en bens do patrimonio cultural (igrexas, monasterios, castelos...). Esta información é patrimonio de todas/os e a súa consulta é indispensabel tanto para estudiantes, investigadores e docentes como para arqueólogos técnicos e resulta imprescindibel que o acceso a esa información sexa facilitado en igualdade de condicións para todos, só asi é posíbel un coñecemento e divulgación razoados e científicos (Blasco 2002).

A Administración autonómica na actualidade non publica informes anuais que resuman as actividades realizadas; non me refiro á publicación de informes e resultados completos, que sería algo inviabel e moi custoso xa que por exemplo no 2003 se autorizaron 38 escavacións, 139 sondaxes, 274 prospeccións e 280 controles, se non, a unha mera relación que indique cantas intervencións se realizaron, quen as levou a cabo, se foi positivo en canto a aparición de restos arqueolóxicos e o perí- 
odo cronolóxico ao que estes pertencen, por exemplo. Simplemente unha información mínima de partida.

A situación editorial desde a Administración é a seguinte:

Facendo referencia a situación da que parto no parágrafo anterior, en 1989 se inicia a Serie Informes dentro da colección Arqueoloxía (esta colección está formada polas series: Informes, Memorias e Investigación, estas dúas últimas comentarémolas mais adiante). O número un desta serie fai unha síntese de todas as actuacións levadas a cabo no ano 1987, divididas en distintos apartados: escavacións, proxectos de investigación territorial, intervencións de urxencia, prospeccións, protección, investigación, inventario e catalogación, concentración parcelaria e gasificación. No número dous, que sae en 1991, se publican os resumos das campañas de 1988 e no número tres, publícase en 1995 cos resultados das campañas de 1989. Desde 1995 ata o ano 2005, non se publicou ningún volume mais desta serie polo que non se coñecen mais datos dese período a través da Administración.

Dentro desta mesma colección aparece por primeira vez publicada en 1985 a Serie Memorias, con tres números monográficos adicados as campañas de escavación de tres castros: o Castro de Vigo (Pontevedra), o Castro de Viladonga (Lugo) e o Castro de Troña (Pontevedra), escritas polos arqueólogos directores das mesmas.

En 1986 aparecen catro títulos mais adicados tamén a campañas de escavación dos xacementos: Castro de Penalba (Pontevedra), Castro de Cameixa (Ourense), Castro de Baroña (A Coruña) e xacemento Galaico-Romano de Santa Tegra (Pontevedra).

En 1987 publícanse as memorias de escavación do Castro de Fozara (Pontevedra) e o Castro da Forca (Pontevedra), en 1988 a memoria do Castro de Coto do Mosteiro (Ourense) e en 1992 a do Castro de Torroso (Pontevedra).

En 1986 aparece a Serie Investigación con unha periodicidade discontinua e irregular, con oito números publicados ata o momento; o último número no ano 2000, con temas moi variados, desde catalogacións, campañas de escavacións, reabilitacións de sitios arqueolóxicos ou teses doctorais, realizados por arqueólogos provintes de distintos ámbitos: administración, centros de investigación públicos ou autónomos.

Na última década, en que os traballos arqueolóxicos se incrementan ano a ano a pasos axigantados (pasamos dun total de 80 actuacións en 1990 a 728 en 2003), o panorama editorial é moi escuro; o volume de información que se atopa disponíbel para a investigación en relación a actividade arqueolóxica en Galiza é inexistente e o mais importante é que apenas existen medios que permitan difundilo . Ademais, esta situación de falta de coñecemento das intervencións realizadas condiciona de 
maneira determinante a consulta dos materiais e datos recuperados en escavacións e prospeccións.

A Universidade galega atópase desvinculada da arqueoloxía de xestión, non responde as exixencias sociais nen proporciona unha preparación adecuada para o traballo de campo a pesar de que se atopa irremediablemente involucrada no devir dos profesionais, pois é a única espendedora de títulos de licenciados, imprescindibeis para o exercicio profesional. A súa incapacidade para adecuar os seus programas formativos aos cambios rexistrados na profesión e as demandas do mercado laboral, a inexistencia dun deseño curricular definido ou dunha titulación específica que permita atinxir un estatuto profesional (polo que ven traballando fai 20 anos a Asociación Profesional de Arqueólogos de España e mais en concreto os intentos continuados de M. A. Querol desde o Departamento de Prehistoria da Universidade Complutense de Madrid $^{2}$ ), constitúen unha das deficiencias principais para a profesión do arqueólogo. A Universidade debería formar aos futuros arqueólogos xestores do patrimonio a través dos seus proxectos e programas de investigación e docencia.

Polo contrario, hai centros públicos que promoven cursos de especialización, congresos, encontros entre profesionais, publicacións..., como o Laboratorio de Arqueoloxía da Paisaxe do Instituto de Estudos Galegos Padre Sarmiento, que xoga un papel fundamental xerando modelos metodolóxicos que permiten aos arqueólogos exercer o seu traballo dentro dun marco ben definido, compatíbel e compartido co traballo de outros profesionais. A pesar das críticas, puxo en marcha unha liña de investigación aplicada que se resume en todas as súas publicacións (unhas 400 entre libros, monografías, artigos en revistas especializadas, comunicacións en congresos nacionais e internacionais...) e que tenta definir as especificacións necesarias para intervir de maneira áxil e produtiva nos diferentes ámbitos do estudo e xestión do patrimonio arqueolóxico. O caracter de "modelos" neste tipo de publicacións otórganllo, ante todo, a falta de exemplos previos que se poidan consultar e contrastar en foros públicos para traballar nese ámbito (Cacheda, 2004).

En canto ao tema da posta en valor en Galiza, hai que recalcar que a administración desde mediados dos 90 estaba instalada nunha rutina de funcionamento incapaz de detectar onde se encontraban os novos retos que debían seguir na difusión do patrimonio arqueolóxico para cumplir de forma plena a función social que se espera da tutela deses bens.

\footnotetext{
${ }^{2}$ Para saber máis sobre as ideas de M. A. Querol pódese consultar o artigo de 1998 La Arqueología en las Universidades Españolas, ou en 2001 La formación y la profesión del arqueólogo. La formación arqueológica universitaria: Un futuro por el que luchar; ambos artigos publicados no Boletín Andalúz do Patrimonio Histórico.
} 


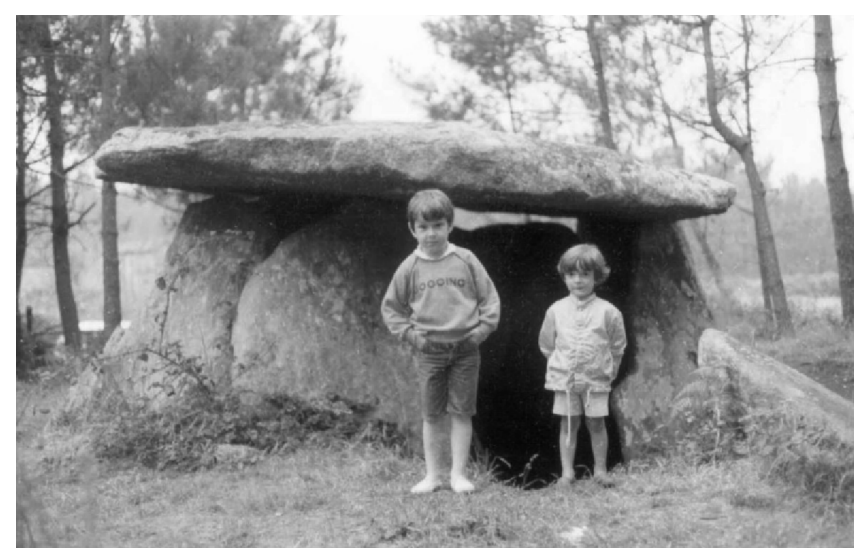

Foto 1: O Dolmen de Dombate nos anos 80, antes de ser escavado.

Advertíase un claro déficit na posta en valor do patrimonio arqueolóxico (sen ir mais lonxe, os resultados da enquisa fannos pensar que ata a chegada da RGPA non houbo outros 'intentos' para iso), pero sabemos que houbo plans de actuación en xacementos que se encontraban en pésimo estado de conservación, fruto de escavacións sistemáticas realizadas sobre todo nos anos 80, aínda que hoxe moitos deles se atopan en estado de abandono (o Dolmen de Dombate foto 1-, é un claro exemplo da deixadez institucional; escavado nos anos 80 por J.M. Bello, que ao finalizar a intervención procedeu a cubrir case a totalidade do xacemento cun plástico cuxa finalidade era protexelo e impedir que medrase a vexetación sobre as zonas escavadas. Trece anos máis tarde o xacemento estaba cuberto de vexetación e inacesíbel para o público, e a Diputación Provincial da Coruña encarga a M. Lestón a escavación e limpeza do xacemento como primeiro paso para a súa musealización. Atopouse cun xacemento gravemente alterado, cuberto de vexetación e coa perda e desprazamento de moitos dos elementos que formaban a coiraza de recubrimento, o forte deterioro que sufriron as improntas de implantación dos ortostatos, e en xeral todos os procesos erosivos que afectaron a masa tumular que ficou ao descuberto naquel momento ${ }^{3}$ fotos $2,3^{4}$ e 4 -).

Hoxe en día as demandas sociais exixen productos de maior calidade, pero as carencias presupuestarias destinadas a arqueoloxía e a falla de modelos teóricos e

\footnotetext{
${ }^{3}$ Para saber máis sobre este 'caso' ver: http://www.dicoruna.es/diputacion/dolmendombate/

${ }^{4}$ Fotos 2 e 3 de Paco Brey, que se poden consultar en: http://www.dicoruna.es/diputacion/ dolmendombate/fotos/index.htm.
} 


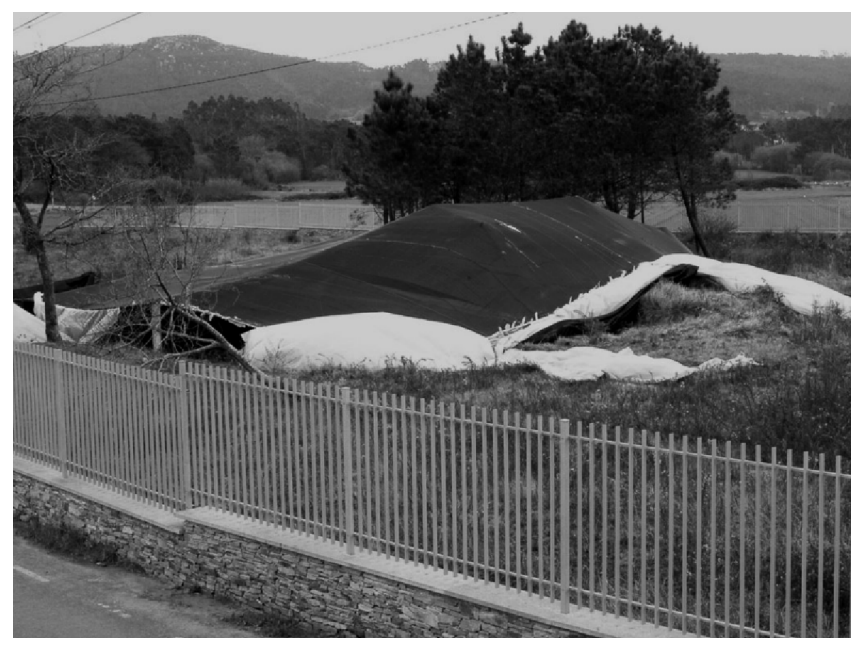

Foto 2: Vista exterior do xacemento arqueolóxico coa cuberta de plástico, solución utilizada nos anos 80 e que continúa hoxe en día. (Foto tomada no ano 2005).

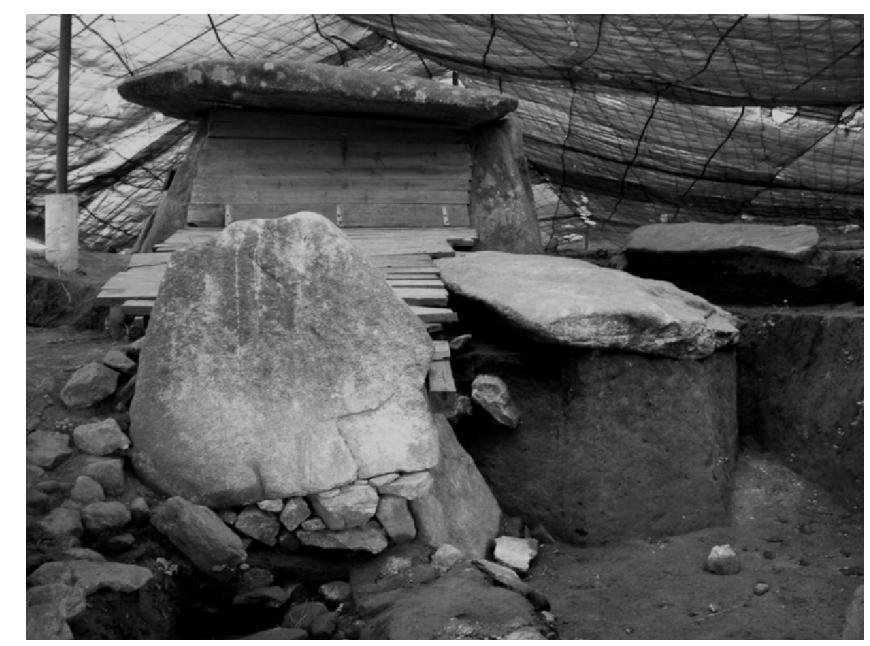

Foto 3: Vista interior do Dolmen despois ds súa escavación por M. Lestón.

interpretativos na posta en valor do patrimonio arqueolóxico, fixeron que, dende a administración, se visen incapaces de afrontar accións importantes encamiñadas a revalorizar os bens arqueolóxicos.

De actuacións parciais de revalorización sobre os xacementos arqueolóxicos máis visitados, se pasa en 1997 a necesidade de crear parques arqueolóxicos. A experiencia doutras Comunidades Autónomas na creación de parques arqueolóxi- 


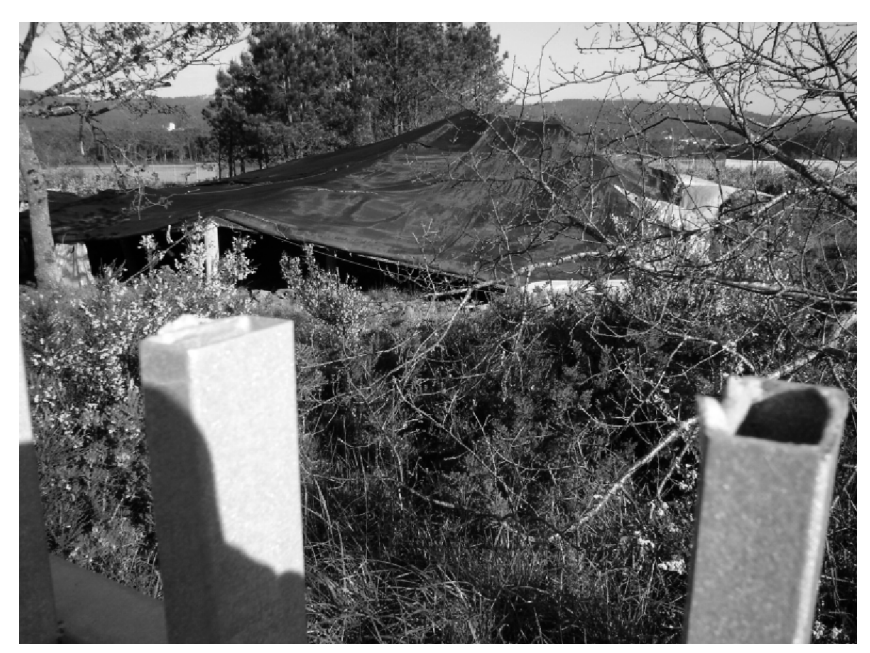

Foto 4: O Dolmen de Dombate en maio do 2005.

cos, os Parques Culturais de Aragón e as Aulas Arqueolóxicas de Castela e León, foron a referencia para fixar as características que se debían contemplar na sua creación, e en 2001, preséntase a RGPA, programa asumido pola Consellería de Cultura, Comunicación Social e Turismo (agora Consellería de Cultura e Deporte) da Xunta de Galiza, que terá como centros de cabeceira catro parques arqueolóxicos creados por instancia do Goberno autonómico, con entidade propia sobre terrenos de titularidade pública.

Dos catro parques proxectados o máis avanzado a día de hoxe é o Parque Arqueolóxico da Cultura Castrexa, que se articula en torno ao castro de San Cibrán de Las en Ourense. En Pontevedra da os seus primeiros pasos o adicado a arte rupestre, cos petroglifos de Campo Lameiro como eixo conductor. Na Coruña, e en concreto a Costa da Morte, verá nacer o de megalitismo. E, como non podía ser doutra forma, Lugo se convertería no corazón do parque dedicado ao mundo romano.

Un factor moi importante a ter en conta co que se enfrenta a Administración a hora de selecionar os xacementos para a súa posta en valor, é que a maior parte deles se atopan en propiedades privadas onde carecen de liberdade de actuación sobre o ben e o seu entorno. Así, nos atopamos coa paradoxa de que a sociedade reclama a posta en valor deses bens arqueolóxicos pero, por outra banda, ampara os dereitos a propiedade privada e salvaguarda os dereitos das persoas físicas ou xurídicas proprietarias deses bens. A adquisición mediante compra pactada ou expropiación resulta moi custosa para as administracións que, ademais, non acostuman ter os seus presupostos orientados para a adquisición deses bens e a cesión 
ou alquiler que dentro do modelo tradicional de propiedade de Galiza é moi difícil de conseguir por períodos dilatados no tempo.

Unha solución sería unha xestión mista do Patrimonio a través da combinación entre a iniciativa privada e a acción pública, coa creación dun programa global que articule as intervencións arqueolóxicas, mediante planos directores en cuxa elaboración deben tomar parte todas as instancias implicadas: promotores privados, a Academia (universidade, centros de investigación e museos), administración e profesionais e resolver esa falsa separación entre técnicos e investigadores. Un exemplo serían estes parques arqueolóxicos: rentabilizar os xacementos facendo deles proxectos empresariais autosostibles e, ao mesmo tempo, crear unha rede de infraestruturas culturais de pequena escala para satisfacer a función social do Patrimonio Arqueolóxico e convertelo nun recurso para o desenvolvimento comunitario.

\section{BIBLIOGRAFÍA}

BARREIRO MARTÍNEZ, David, Arqueología y Sociedad: Propuesta Epistemológica y Axiológica para una Arqueología Aplicada. Tesis Doctoral. Inédita 2005.

BLASCO BOSQUED, María Concepción, Ponencia en las Primera Jornada sobre Arqueología Profesional en la Comunidad de Madrid. Madrid: Sección de Arqueología del Colegio Oficial de Doctores y Licenciados en Filosofía y Letras y en Ciencias de la Comunidad de Madrid, 2002. [en línea] En: http://www.cdlmadrid.es/arq/cursoarqprofesional/cursoarqprofesional.html [consulta: 25/11/04].

CACHEDA PÉREZ, María, Arqueología Aplicada: síntesis de resultados en la gestión del impacto del Plan Eólico de Galicia (1995 - 2001). Arqueología Aplicada 24-25. Teruel: Seminario de Arqueología y Etnología Turolense, Instituto de Estudios Turolenses 2005, 217-30.

CACHEDA PÉREZ, María, An Observatory of Proffesional Archaeology. Actas del Congreso Internacional de Arqueología de la European Association of Archaeologists, 10 th Annual Meeting. Lyon, 2004, 276.

GARCÍA FERRANDO, Manuel, La entrevista. En M. García Ferrando, J. Ibáñez y F. Alvira: El análisis de la realidad social. Métodos y Técnicas de investigación. Madrid: Alianza, 1993.

INFANTE ROURA, Faustino, La revalorización del patrimonio arqueológico desde la Administración. La Revalorización del Patrimonio Arqueológico. Santiago de Compostela: Curso de Especialización Gestión Arqueológica del Patrimonio Cultural, Modulo 7, Laboratorio de Arqueoloxía e Formas Culturais, Universidade de Santiago de Compostela, 2001, 27-28.

MARTÍNEZ DÍAZ, Belén, Veinte años de Arqueología en el Estado de las Autonomías. Historiografía de la Arqueología Española. Las instituciones. Serie Cursos y Conferencias 3 del Museo de San Isidro. Madrid, 2002, 223-247.

ROJAS TEJADA, Antonio José - FERNÁNDEZ PRADOS, Juan Sebastián - PÉREZ MELÉNDEZ, Cristino, Investigar mediante encuestas. Fundamentos teóricos y aspectos prácticos. Madrid, 1998. 
TALLÓN NIETO, María Jesús - RODRÍGUEZ PUENTES, Eugenio - INFANTE ROURA, Fausto REY GARCÍA, José Manuel, A Rede do Patrimonio Arqueológico. Santiago de Compostela, 2004. 